\title{
0 ensino pela pesquisa: interlocuções com Paulo Freire na docência em biblioteconomia
}

\author{
Jorge Santa Anna*
}

Artículo recibido:
7 de noviembre de 2017
Artículo aceptado:
23 de agosto de 2018
Artículo de investigación

\section{Resumen}

El objetivo de este artículo es relatar y confirmar la propuesta freireana de enseñar aprendiendo al ser aplicada en el contexto de la Ciencia de la Información, una de las áreas que más exige habilidad en cuanto a los procedimientos de investigación y para compartir el conocimiento. El artículo discurre acerca de la práctica de la investigación aliada al diálogo y al intercambio de informaciones, procedimientos adoptados por un docente de Biblioteconomía en una universidad. Presenta los resultados alcanzados a partir de la aplicación de procedimientos de investigación en una disciplina respecto de la formación académica de bibliotecarios. Refuerza la importancia de esta práctica en el ejercicio de la docencia y la contribución del

* Universidad Federal de Minas Gerais, Brasil. professorjorgeufes@gmail.com

INVESTIGACIÓN BIBLIOTECOLÓGICA, vol. 32, núm. 77, octubre/diciembre, 2018, México,
ISSN: 2448-8321 pp. 59-72 59 
aprendizaje compartido en las aulas. La metodología adoptada caracteriza el estudio como investigación descriptiva, de abordaje cualitativo, con técnicas de observación, relato de experiencia y entrevista. Se confirmó la viabilidad en adoptar la investigación y compartir el conocimiento en la docencia en Biblioteconomía, teniendo en cuenta el dominio crítico-reflexivo proporcionado al alumnado, así como la satisfacción de esos sujetos en cuanto al uso de ese método de enseñanza en la formación académica.

Palabras clave: Enseñanza de la Investigación; Docencia en Biblioteconomía; Enseñanza- Aprendizaje; Método Freireano de Enseñanza

\title{
The teaching for the research: interlocutions with Paul Freire in teaching in library \\ Jorge Santa-Anna
}

\begin{abstract}
This paper examines the Freirean proposal for teaching/learning, specifically in the field of Information Science, a field that requires both rigorous research procedures and knowledge sharing, and discusses the approach to research, adopted by a university Librarianship lecturer, that is allied with dialogue and exchange of information. Results from the application of such research procedures during the academic training of librarians are reported that serve to reinforce the importance of shared teaching/learning in classrooms. This study employs a descriptive research methodology, using a qualitative approach that includes observation techniques, experiential reporting and interviews. Through the critical-reflexive milieu provided to students, the practicality of sharing knowledge in practice of teaching in Librarianship is confirmed. Moreover, student satisfaction was enhanced through the deployment of this teaching method in academic training.
\end{abstract}

Keywords: Teaching by Research; Teaching in Librarianship; Teaching-learning; Freirean Method of Teaching 


\section{INTRODUÇÃO}

A prática educativa acompanha o ser humano infinitamente, perpassando $\mathrm{A}_{\text {as diversas fases da vida. Desde os ensinamentos familiares, à educação }}$ básica e profissional, até à vivência diária nas relações de trabalho, o ser humano está em constante aprendizado. Essa prática manifesta-se em todas as áreas do conhecimento, intensificando-se, sobremaneira, no período correspondente à formação acadêmico-profissional, haja vista a preparação técnica e humanista do indivíduo para uma atuação efetiva no contexto social.

No âmbito da formação acadêmico-profissional, o papel desempenhado pelos docentes é de suma importância. O exercício da docência constitui um dos fazeres mais estratégicos e provocativos no que se refere à aquisição/ampliação de conhecimento. $\mathrm{O}$ ato de ensinar requer a preparação prévia do docente, por meio de estudo e pesquisa que o capacite ao domínio específico de determinada temática ou área do conhecimento, viabilizando o processo de produção de conhecimento individual.

Contudo, é louvável e ainda mais produtivo, aquele que conduz seus métodos de ensino por meio da filosofia do ensinar aprendendo. Além de produzir conhecimento individual e transmiti-lo ao alunado, o docente, nessa concepção, ao mesmo tempo que ensina, também recebe conhecimentos do alunado, firmando um processo educativo recíproco e interativo, com vistas a despertar uma produção coletiva de conhecimento.

A sala de aula transforma-se em um ambiente de socialização, atuando o docente como mediador que conduz as atividades mútuas de ensino-aprendizagem. Essa proposta de ensino revoluciona a forma de educação empregada de forma centralizada na figura do professor como centro das atenções, caracterizando um processo de alienação. As propostas freireanas ${ }^{1}$ consideram a incompletude do ser humano, logo, o professor também está em constante aprendizado. Essa incompletude é justificada porque é "[...] impossível saber-se incabado e não se abrir ao mundo e aos outros à procura de explicação, de respostas a múltiplas perguntas" (Freire, 2006: 136).

Assim, o professor é o personagem que ensina e aprende ao mesmo tempo. Mantendo uma relação pacífica e conjunta com os alunos, trocando com eles informação, o professor capacita-os a adquirir competências e habilidade essenciais para resolver problemas rotineiros presentes nas relações sociais, como também, ter capacidade em comunicar-se, tomar decisões, fundamentar suas ideias, enfim, relacionar-se socialmente.

1 Refere-se aos ensinamentos propostos por um dos maiores teóricos e educadores do Brasil, Paulo Freire. O pensamento desse teórico revolucionou a pedagogia mundial, propondo novos métodos de ensino, em prol de uma educação libertadora e crítica (Guimarães et al., 2017). 
O objetivo de formar alunos críticos, seguros e participativos, tendo em vista concretizar seus objetivos de vida na sociedade deve ser uma das preocupações dos professores da sociedade atual. Isso porque, segundo Behrens (1999, em Rodrigues, 2010: 148), "a sociedade passa a exigir profissionais que tenham capacidade de tomar decisões, que sejam autônomos, que produzam com iniciativa própria, que saibam trabalhar em grupo, que partilhem suas conquistas e que estejam em constante formação".

A fim de adquirir conhecimento e formar indivíduos transformadores é preciso, também, que o professor adote métodos que incentive os discentes ao hábito da pesquisa. Ensinar por meio da pesquisa desperta nos aprendizes o espírito investigativo e inovador. Assim, segundo Piaget (1974: 18), o verdadeiro professor é aquele que "[...] deixa de ser apenas um conferencista e estimula a pesquisa e esforço, em lugar de contentar-se em transmitir os problemas já solucionados".

Mesmo cientes da importância do processo de pesquisa na educação superior, muitos desafios ainda perfazem a consolidação dessa prática, pois a pesquisa tem sido ensinada de uma maneira ineficiente, e, possivelmente com algum efeito colateral negativo. Considera-se importante introduzir o estudante no processo real de conduzir pesquisa e não apenas em ler sobre o assunto (Witter, 1987).

Sendo assim, este estudo propõe reflexões sobre a importância da prática da pesquisa no exercício da docência e a contribuição do compartilhamento de conhecimento nas salas de aula, considerando o pensamento de Paulo Freire como fundamental para o sucesso do processo educativo no decurso da formação acadêmico-profissional.

O presente texto narra a prática da pesquisa aliada ao método freireano, procedimentos esses adotados por um docente do Curso de Biblioteconomia em uma universidade. Discorre acerca dos procedimentos adotados pelo docente no intuito de viabilizar a pesquisa, o interesse e a participação conjunta entre aluno e professor, com vista a concretizar a construção coletiva de conhecimento. Além disso, o estudo apresenta, por meio de método avaliativo, a percepção dos discentes quanto às metodologias e didática adotadas pelo professor no decorrer da disciplina.

A proposta aqui formulada é conduzida por meio de uma pesquisa descritiva, de abordagem qualitativa, com técnicas de observação, relato de experiência e entrevista, considerando as atividades e vivência prática de um docente no contexto da formação acadêmica em Biblioteconomia/Ciência da Informação no Brasil. 


\section{Metodologia}

No intuito de relatar a aplicabilidade das propostas educativas de Freire (2006), na docência em Biblioteconomia, de modo a demonstrar a viabilidade da prática colaborativa e de pesquisa adotada no ensino dessa área de conhecimento, a pesquisa aqui apresentada caracteriza-se como descritiva, de abordagem qualitativa, com técnicas de observação, relato de experiência e entrevista.

O estudo manifesta-se com essas características metodológicas porque: descreve a percepção dos alunos acerca do método adotado na condução de uma disciplina (pesquisa descritiva); apresenta informações oriundas da literatura e das opiniões de discentes, o que não requer a quantificação/mensuração desses dados (pesquisa qualitativa); utiliza de constatações advindas de comportamentos monitorados (observação); relata atividades, fatos e ocorrências de uma realidade prática (relato de experiência); e, por fim, utiliza dados coletados em um processo de avaliação, contendo a opinião de sujeitos sobre um determinado objeto (entrevista).

Os dados coletados para aferição dos resultados, a princípio, foram extraídos da literatura até então publicada sobre métodos de ensino, com foco na obra de Paulo Freire. Esse diálogo com outras pesquisas é de fundamental importância para proporcionar consistência e comparação dos resultados alcançados com este estudo. Portanto, utilizando-se de leituras, adentrou-se a artigos científicos e livros das áreas de Educação e Biblioteconomia/Ciência da Informação, a fim de fomentar o discurso e os argumentos em comparação com os dados que foram levantados da realidade prática e devidamente interpretados.

Além disso, também se coletou dados por meio do monitoramento de uma disciplina ofertada no curso de Biblioteconomia de uma universidade. A análise dos procedimentos adotados pelo professor consolidou-se por meio da aplicação da técnica de observação e de entrevista.

O estudo de observação foi realizado junto às atividades ministradas pelo professor, incentivando os discentes a pesquisarem as temáticas propostas no programa de disciplina. Já a entrevista foi aplicada aos alunos, no final da disciplina, no intuito de analisar a percepção deles quanto a esse método de ensino utilizado pelo docente. Essas técnicas de coleta de dados, considerando a realidade prática e o acompanhamento do pesquisador, ao longo de sua experiência como docente, caracterizam, metodologicamente, o relato de uma experiência.

Em suma, no que se refere ao instrumento de coleta de dados junto aos alunos, foi elaborada uma pergunta aberta, de modo que os sujeitos descrevessem 
em papel que lhes foi entregue, os pontos positivos e negativos da disciplina, considerando as metodologias de ensino adotadas, como: leituras constantes, pesquisas na literatura sobre temas específicos, rodas de conversa, seminários, trabalhos em grupo, elaboração de resumos e fichamentos, dentre outras.

Os dados coletados da realidade prática, a interlocução com os dados discorridos na literatura e os resultados possíveis alcançados a partir dessas análises são descritos na seção seguinte.

\section{ApresentaÇÃo e ANÁlise de Resultados}

A disciplina ministrada pelo docente de Biblioteconomia foi "Formação e desenvolvimento de coleções (FDC)", disciplina essa ofertada no sétimo (penúltimo) período do curso. A turma continha um total de 26 alunos, os quais encontravam-se em fase final da Graduação, alguns até iniciando os trabalhos de conclusão de curso (TCCs). Todavia, faz-se necessário destacar que eles não estavam familiarizados com o método da pesquisa, uma vez que o curso e a própria universidade estimula a prática da pesquisa, com maior intensidade, no momento da elaboração dos TCCs.

O professor, no primeiro dia de aula, discorreu acerca do método freireano, assim como demonstrou as constantes atividades de pesquisa que norteariam as três unidades da disciplina. Como não haveria avaliação final escrita, os alunos seriam avaliados conforme o empenho e engajamento com as pesquisas e consequente produção de textos. Em virtude de a disciplina de FDC possui características teóricas, esse fato proporcionou a aplicação das técnicas de pesquisa, sobretudo na primeira unidade, quando se estuda a evolução histórica das coleções ao longo dos tempos.

Foi possível observar, a priori, um certo espanto e admiração dos alunos, acerca das atividades que seriam desenvolvidas, sobretudo no que se refere à aplicação de muitos trabalhos e à ausência de avaliação formal, como o público estava acostumado. Essa admiração inicial também foi constatada no estudo de Grillo et al. (2016), o qual defendeu haver necessidade, antes de adotar essa metodologia, de "[...] reflexão e de amadurecimento, o que implica a autoaceitação do professor como mediador no ensino, e do aluno como protagonista de sua aprendizagem" (Grillo et al., 2016: 1).

A cada aula, o professor utilizava estratégias que convidavam os alunos à participação. $\mathrm{O}$ ato de fazer perguntas individuais, de aplicar atividades para casa, sendo discutidas na aula seguinte, de indicar livros e artigos de fácil leitura constituem alguns dos procedimentos que motivavam ou convidavam o alunado a trocar conhecimentos com o professor. 


\section{Discussão}

Por meio da análise aos diversos relatos constantes na literatura, importante citar o trabalho de Isaia (2006), para quem, a prática de pesquisa, diálogo e interação entre alunos e professor consolida a chamada aprendizagem compartilhada, que pode ser definida como um processo de construir conhecimento de forma colaborativa no âmbito do ensino nas universidades, "[...] em que docentes e alunos constroem, por meio de uma aprendizagem colaborativa, conhecimento profissional compartilhado" (Isaia, 2006: 77).

$\mathrm{Na}$ unidade I da disciplina foi apresentado o percurso histórico do processo de FDC. A turma foi dividida em quatro diferentes grupos, estando cada um responsável em pesquisar como as coleções bibliográficas eram monitoradas nos períodos históricos, como: na Antiguidade, Idade Média, Idade Moderna e Contemporânea.

Em cada aula, os grupos traziam as fontes que haviam pesquisados e contribuíam com o debate mediado pelo docente. As nomenclaturas mais importantes deveriam ser esclarecidas, como: bibliófilos, copistas, armazenamento de coleções, preservação/conservação, bibliotecas minerais e vegetais, códices, papiro, gestão das coleções, desbastamento, planejamento da coleção, dentre outras.

Percebe-se a fundamental importância em motivar os alunos a pesquisar em diferentes fontes, sejam livros, artigos científicos ou meramente informativos, documentos arquivísticos, dentre outras, uma vez que essa prática familiariza o pesquisador com as estruturas e especificidades de cada tipo de fonte analisada, facilitando, portanto, a localização do assunto que está sendo pesquisado.

Além de treinar o aluno com o uso das fontes de pesquisa, o ato de pesquisar permite o entendimento acerca de conceitos, terminologias, teorias, leis, paradigmas e fatos históricos, elementos de suma necessidade para enriquecer o vocabulário do pesquisador, como permitir que ele entenda as questões teóricas e epistemológicas, para, posteriormente, aplicar o conhecimento produzido. Com esse estímulo à pesquisa nas fontes e o compartilhamento das descobertas, pode-se confirmar que "saber ensinar não é transferir conhecimento, mas criar as possibilidades para a sua própria produção ou a sua construção" (Freire, 1997: 52 em Ferreira, 2017: 11).

$\mathrm{Na}$ unidade II, abordaram-se as etapas do processo de FDC, enfocando no Modelo Holístico de Evans, o qual propõe a delineação de seis etapas: estudo da comunidade, política, seleção, aquisição, desbaste e avaliação. Cada uma 
dessas etapas foi entregue aos grupos que realizaram pesquisas e socializaram com a turma por meio de seminários e rodas de conversa ${ }^{2}$.

Tendo em vista a aplicação dessas técnicas de ensino e a liberdade em pesquisar que foi conferida aos alunos, evidencia-se que esse tipo de ensino viabiliza a reconstrução contínua do conhecimento, de modo que novos pontos de vista surgem, evidenciando que não há verdade absoluta (Bolzan, 2002). Assim,

O conhecimento é gerado e co-construído coletivamente, e produzido na interatividade entre duas ou mais pessoas que dele participam, constituindo-se o núcleo da atividade. Tarefas conjuntas provocam a necessidade de confrontar pontos de vista divergentes, acerca de uma mesma atividade, o que possibilita a descentralização cognitiva e se traduz no sociocognitivo que mobiliza as estruturas intelectuais existentes e obriga os sujeitos a reestruturá-las (Bolzan, 2002: 53).

No bojo das atividades realizadas pelos alunos e a apresentação dessas atividades, importante lembrar que o processo de pesquisa não se constituía, tão somente, de leitura. O grupo também deveria, no dia da apresentação, trazer um resumo expandido da temática que estava pesquisando. Foram ensinadas técnicas de leitura, de redação e de estrutura e normalização de trabalhos técnico-científicos.

A interação entre pesquisa e produção de textos faz parte do universo do estudante universitário. Os procedimentos adotados para leitura, interpretação, elaboração e apresentação seguem um formalismo que consolida os rigores científicos, logo proporcionar habilidades ao alunado quanto a esse "modismo" é uma estratégia interessante dos docentes no decurso das atividades disciplinares. Além de ensinar esse formalismo, faz-se necessário motivar o aluno a atribuir significado àquilo que elabora (Marquesin, Benevides e Baptista, 2011).

Por fim, na unidade III, os alunos pesquisaram o que a literatura mencionava sobre processos de FDC em diferentes modalidades de biblioteca. Assim, cada grupo fez levantamentos bibliográficos, acompanhamento e visita a uma modalidade de biblioteca, entrevistando o bibliotecário e observando como os processos eram realizados, comparando com as recomendações da literatura. As pesquisas de campo foram socializadas em sala, no último dia de aula, sendo que cada contexto analisado foi comparado com os demais.

2 Essas técnicas de ensino caracterizam-se por manifestarem-se como importantes instrumentos a serem utilizados como prática metodológica de aproximação entre os sujeitos no cotidiano pedagógico. É por meio do diálogo inerente a essas técnicas que o conhecimento é compartilhado entre alunos e professores (Melo e Cruz, 2014). 
Essa atividade proposta pelo professor promoveu a integração entre teoria e prática, de modo a tonar mais visível para os aprendizes do que é ensinado na sala de aula. No âmbito da Biblioteconomia/Ciência da Informação, conhecer a realidade social e as instituições bibliotecárias é um pressuposto para planejar quaisquer serviços de informação (Almeida, 2011). Além disso, ao demonstrar a realidade social das instituições e da sociedade como um todo o docente assume frente a seus alunos "[...] um compromisso com os destinos do país. Compromisso com seu povo. Com o homem concreto. Compromisso com o ser mais deste homem" (Freire, 2007: 25).

Nesse contexto, acredita-se ser viável a integração entre teoria e prática na condução de uma disciplina do ensino superior. Isso porque viabiliza comunhão dos objetivos principais da universidade, por meio da tríade ensino, pesquisa e extensão, sendo que essas três dimensões se complementam (Emmel e Krul, 2017).

Acreditamos que a Docência no Ensino Superior está implicada em ensino, pesquisa e extensão, formando uma tríade articulada entre si, uma vez que a atividade de ensino também pode ser realizada sob uma atitude investigativa, e assim sucessivamente a extensão, que se relaciona a pesquisa, pois implica a produção de conhecimentos vinculados com a vida em sociedade (Emmel e Krul, 2017: 1, grifo nosso).

A investigação in loco e a devida apresentação das experiências vivenciadas por cada grupo de trabalho demonstrou o quanto os alunos já possuem algum conhecimento acerca da realidade, dos produtos, serviços e recursos presentes nas unidades de informação. Por meio das visitas, os alunos aperfeiçoaram o conhecimento, como também identificaram problemas e casos de sucesso relativos às atividades do profissional no mercado de trabalho. Esse resultado se assemelha às mesmas percepções de alunos alcançadas com o estudo de Almeida (2011), acerca das atividades propostas em disciplinas do Curso de Biblioteconomia, como: Disseminação da Informação, Fontes de Informação e Ação Cultural.

Vê-se que os alunos estiveram envolvidos com pesquisa, durante o desenvolvimento da disciplina FDC. O professor reportou-se como um verdadeiro orientador das práticas de pesquisa. Por consequência dessa metodologia, foi possível perceber que a sala de aula transformou-se em um ambiente de compartilhamento do conhecimento, um espaço para diálogo e relações harmoniosas, além de se fortalecer, nesse contexto interativo, ações como: indagação, refutação, confirmação, ética, confiabilidade, precisão, 
transparência e ajuda mútua, elementos esses primordiais para garantir boas práticas no fazer científico e profissional.

A fim de analisar a percepção dos alunos a respeito do método adotado, o docente aplicou um processo avaliativo, solicitando a descrição dos pontos positivos e negativos. No dia da aplicação do questionário, estavam em sala, 20 alunos, sendo que foram devolvidos um total de 18 questionários. Em virtude das respostas serem muito parecidas, apresentam-se, por meio do quadro 1 , os principais pontos descritos, sendo que a maioria registrou satisfação quanto ao método adotado na disciplina de FDC.

\begin{tabular}{|c|c|}
\hline Pontos positivos sobre o método de ensino & $\begin{array}{l}\text { Pontos negativos sobre o método } \\
\text { de ensino }\end{array}$ \\
\hline $\begin{array}{l}\text { "Foram aulas em que todos permaneceram atentos, } \\
\text { se empenhando nas pesquisas" }\end{array}$ & $\begin{array}{l}\text { "As aulas foram tão boas que ficáva- } \\
\text { mos torcendo para que chegasse o } \\
\text { dia da disciplina. Ficava triste quando } \\
\text { a aula acabava. Único ponto negativo } \\
\text { foi a intervenção do professor no } \\
\text { final das apresentações, apresen- } \\
\text { tando os erros dos alunos. Isso pode } \\
\text { constranger alguns. Do resto foi tudo } \\
\text { ótimo" }\end{array}$ \\
\hline $\begin{array}{l}\text { "O método de pesquisa conferiu a nós, maior autono- } \\
\text { mia e autoconfiança" }\end{array}$ & $\begin{array}{l}\text { "Muito trabalho para fazer. Se fosse } \\
\text { só uma disciplina, mas fazemos } \\
\text { várias em um período" }\end{array}$ \\
\hline $\begin{array}{l}\text { "Evoluí muito como pessoa e como pesquisadora. } \\
\text { Aprendi a fundamentar minhas ideias e defendê-las } \\
\text { com embasamento" }\end{array}$ & \\
\hline $\begin{array}{l}\text { "A pesquisa dá aos alunos autoridade, clareza, inde- } \\
\text { pendência e objetividade. Incentiva-nos a descobrir } \\
\text { nossas potencialidades" }\end{array}$ & \\
\hline $\begin{array}{l}\text { "A melhor disciplina que já tivemos. Foi-nos dada a } \\
\text { chance de vivenciar o sentido de uma universidade } \\
\text { que é não apenas aprender, mas construir e ensinar" }\end{array}$ & \\
\hline $\begin{array}{l}\text { "Aulas foram dinâmicas, democráticas, levando os } \\
\text { alunos a pensarem criticamente sobre o tema FDC" }\end{array}$ & \\
\hline
\end{tabular}

Quadro 1. Descrição dos principais pontos avaliados pelos alunos

Fonte: dados das pesquisa (2015)

A partir da fala dos discentes, entende-se que o método adotado na condução da disciplina de FDC tornou-os satisfeitos. Mais que isso, pois, ao analisarmos algumas falas, encontramos expressões que demonstram o quanto produtiva e transformadora foi a disciplina na vida desses futuros bibliotecários. Pode-se inferir que, algumas características como autonomia, autoconfiança, 
segurança, pensamento crítico e embasamento de ideias representam a mudança de postura do profissional e não apenas uma evolução ou desempenho na disciplina.

Importante destacar sobre a diversidade de atividades e as inovações que a disciplina proporcionou aos alunos. Se, no iniciar da disciplina, o professor percebeu espanto por parte do alunado, no final da disciplina, manifestou-se o engajamento dos discentes com as técnicas de pesquisa, o aperfeiçoamento no ato de discursar, o encorajamento para atuação frente aos desafios do mercado de trabalho, como também o reconhecimento do que realmente é a profissão e o fazer científico.

Esse resultado pode ser constatado por meio do relato de um dos respondentes: "Essa disciplina clareou muitas coisas referentes à nossa atuação como profissional bibliotecário. Me evoluí como estudante, pesquisadora e como profissional. Gostei muito da variedade de atividades realizadas". A respeito desse resultado avaliativo, dialogamos com Pimenta e Anastasiou (2008: 103, grifo nosso):

O ensino na universidade caracteriza-se como um processo de busca e de construção científica e crítica de conbecimentos. As transformações da sociedade contemporânea consolidam o entendimento do ensino como fenômeno multifacetado, apontando a necessidade de disseminação e internalização de saberes e modos de ação (conhecimentos, conceitos, habilidades, procedimentos, crenças, atitudes).

Outro ponto que torna-se pertinente analisar com mais detalhe diz respeito à mudança de comportamento e postura do aluno quando insere-se no universo da pesquisa. Segundo um dos entrevistados: "A pesquisa dá aos alunos autoridade, clareza, independência e objetividade. Incentiva-nos a descobrir nossas potencialidades". Assim, o aluno adquire maior segurança quando toma suas decisões ou faz seus julgamentos, algo de extrema importância ao se inserir no mercado de trabalho. Além disso, segundo Bastos et al. (2010), a pesquisa, assim como a iniciação científica e projetos de extensão, oportuniza a vocação no alunado a partir dos fazeres investigativos, por meio de uma postura interventiva e crítica no que está sendo pesquisado e será descoberto.

Dos 18 relatos obtidos com a aplicação da avaliação, por escrito, é possível identificar a superação de pontos positivos quanto aos pontos negativos. Identificaram-se, como pontos negativos, os seguintes: 1 - muito trabalho para realizar, e 2 - sugestões do professor, apresentadas diante de toda a turma, acerca de melhoria na forma de os alunos apresentarem os trabalhos.

Essas indicações negativas são válidas, uma vez que podem ser utilizadas como ponto de reflexão do professor, haja vista melhorar continuamente o 
seu trabalho, de modo a adequar-se às necessidades do público e atingir níveis mais elevados de excelência e qualidade. No entanto, é importante considerar, outrossim, que essas questões apontadas pelos alunos são complexas, sobretudo a intervenção no final dos seminários.

As diferentes formas de avaliação e diálogo com os alunos, como também a reflexão acerca de melhorias para o aprendizado desses sujeitos deve ser uma constante no contexto da sala de aula, sobretudo no ambiente universitário. Estabelecer formas de diálogo com os alunos de modo a transparecer a necessidade de melhoria é uma ação que se justifica, pois, no processo de ensino aprendizagem isso não é desnecessário, ao contrário, é imprescindível para despertar o aprendizado.

A esse respeito, dialogamos com Brito (2012: 4), para quem a verdadeira dimensão e direção da avaliação "[...] é a aprendizagem a cada momento, a cada passo e de forma contínua e dinâmica [...]". Assim, entendemos que essa conduta do professor não deve deixar de ser aplicada, dada a sua importância, no entanto, é preciso pensar em formas mais sensatas e discretas de realizar as correções.

\section{Considerações finais}

Este estudo apresentou o método de ensino adotado na disciplina de FDC, do curso de Biblioteconomia de uma universidade. Constatou que o ensino pela pesquisa, aliado ao diálogo e ao compartilhamento de conhecimento, bases da filosofia freireana, despertou inúmeras condutas ao alunado, como: empenho, participação intensa, motivação, interesse e interação.

Essas são algumas das características fundamentais do profissional do futuro, em frente a uma sociedade mutante e desafiadora. Os resultados comprovam que o ensino pela pesquisa e a construção coletiva do conhecimento são estratégias pedagógicas viáveis, haja vista alcançar o processo de ensino-aprendizagem. No contexto da Biblioteconomia, infere-se que esse método é ainda mais necessário, em virtude de envolver uma das áreas de atuação desse profissional: o ramo da pesquisa e, atrelado a esse fazer, manifesta-se o processo de busca e recuperação de fontes de informação.

Com efeito, é possível confirmar a relevância da proposta freireana do ensinar aprendendo, especificamente no contexto da Ciência da Informação, uma das áreas que mais exige habilidade quanto aos procedimentos de pesquisa e compartilhamento de conhecimento. Confirmou-se a viabilidade em se adotar a pesquisa e a aprendizagem compartilhada, além das relações democráticas e dialógicas firmadas entre aluno e professor, no âmago 
da docência em Biblioteconomia, haja vista o domínio crítico-reflexivo proporcionado ao alunado, como também a satisfação desses sujeitos quanto ao uso desse método de ensino na formação acadêmica.

Recomendam-se estudos futuros, acerca das estratégias utilizadas em outras disciplinas (pesquisa de campo) e a devida comparação entre essas disciplinas, como também pesquisa documental, por meio da análise à ementa das disciplinas ofertadas na Graduação e do projeto político pedagógico do curso, a fim de verificar a filosofia freireana contida nesses documentos curriculares. Ademais, o estudo direciona a uma futura análise comparativa dessa filosofia entre os diversos cursos ofertados na universidade.

\section{REFERÊNCIAS}

Almeida, Carlos Cândido. 2011. "Profissionais mediadores da informação: experiências didático-pedagógicas em dois cursos de biblioteconomia brasileiros”. Revista EDICIC 1 (3): 1-17. Acesso em: 28 fev. 2018. https://repositorio.unesp.br/bitstream/handle/11449/115137/ISSN2236-5753-2011-01-03-01-17.pdf? sequence $=1$

Bastos, Flávia, Fernanda Martins, Mara Laves, Mauro Terra e Camila Souza Lemos. 2010. "A importância da iniciação científica para os alunos de graduação em biomedicina”. Revista Eletrônica Novo Enfoque 11 (11): 61-66. Acesso em: 28 fev. 2018. http://www.castelobranco.br/sistema/novoenfoque/files/11/artigos/08.pdf

Bolzan, Dóris Pires Vargas. 2002. Formaçao de professores: compartilhando e reconstruindo conbecimentos. Porto Alegre: Mediação.

Brito, Rosa Maria Cavalcanti. 2012. O professor, a aprendizagem significativa e a avaliação: base para o sucesso escolar do aluno. Acesso em: 28 mar. 2018. http://www. anpae.org.br/seminario/ANPAE2012/1comunicacao/Eixo03_38/Rosa\%20Maria\%20Cavalcanti\%20Brito_int_GT3.pdf

Emmel, Rúbia e Alexandre Jose Krul. 2017. "A docência no Ensino Superior: reflexões e perspectivas”. Revista de Ensino Superior 3 (1): 1-17. Acesso em: 15 mar. 2018. http://dx.doi.org/10.18256/2447-3944/rebes.v7n1p42-55

Ferreira, Glória Izabel. 2017. A prática pedagógica do professor de Biblioteconomia. Acesso em: 28 mar. 2018.

http://www.lume.ufrgs.br/bitstream/handle/10183/10202/000294923.pdf

Freire, Paulo. 2006. Pedagogia da autonomia: saberes necessários à pratica educativa. 33. ed. São Paulo: Paz e Terra.

Freire, Paulo. 2007. Educação e mudança. 30ª ed. Rio de Janeiro: Paz e Terra.

Grillo, Marlene Correro, Délcia Enricone, Patrícia Mattei e Josele Benedito Ferreira. 2016. "Ensino e pesquisa com pesquisa em sala de aula". UNIrevista 1 (2): 1-11. Acesso em: 28 mar. 2018. http://faculdadebarretos.com.br/wp-content/ uploads/2015/11/pesquisa-sala-de-aula2.pdf

Guimarães, Alessandro, Ednalva Gutierrez Rodrigues, Fernanda M. B. Camargo, Joelma de Souza Mendes Rizzo, Margarete Sacht Goes e Shenia D’Arc Venturim Cornélio. 2017. "A palavra é... Paulo Freire”. Pró-Discente: Caderno de Produção 
Acadêmico-Cientifica 23 (1): 64-81. Acesso em: 28 mar. 2018. www.periodicos. ufes.br/PRODISCENTE/article/download/18600/12608

Isaia, Sílvia Maria de Aguiar. 2006. "Desafios à docência superior: pressupostos a considerar", em Docência na Educação Superior, organizado por Dilvo Ristoff e Palmira Sevegnani, 63-84. Brasília: INEP.

Marquesin, Denise Filomena Bagne, Cláudio Roberto Benevides e Denise Cristina Baptista. 2011. "Leitura e escrita no ensino superior". Revista de Educação 14 (17): 9-28. Acesso em: 28 mar. 2018. http://www.pgsskroton.com.br/seer/index. php/educ/article/viewFile/1801/1714

Melo, Marcia Cristina Henares de e Gilmar de Carvalho Cruz. 2014. "Roda de conversa: uma proposta metodológica para a construção de um espaço de diálogo no Ensino Médio”. Imagens da Educação 4 (2): 31-39. Acesso: 20 mar. 2018. http:// dx.doi.org/10.4025/imagenseduc.v4i2.22222

Piaget, Jean. 1974. Educar para o futuro. Rio de Janeiro: Fundação Getúlio Vargas.

Pimenta, Selma Garrido e Léa das Graças Anastasiou. 2008. Docência no Ensino Superior. 3 ed. São Paulo: Cortez.

Rodrigues, Mara Eliane Fonseca. 2010. "A abordagem do ensino com pesquisa: uma alternativa pedagógica para o ensino de biblioteconomia e ciência da informação". TransInformação 22 (2): 147-167. Acesso: 05 abr. 2018. http://dx.doi. org/10.1590/S0103-37862010000200005

Witter, Geraldina Porto. 1987. "O ensino de metodologia científica em biblioteconomia: algumas considerações”. Ciência da Informação 16 (2): 145-149. Acesso em: 28 mar. 2018. http://revista.ibict.br/ciinf/article/view/257

Para citar este texto:

Santa Anna, Jorge. 2018. "O ensino pela pesquisa: interlocuções com Paulo Freire na docência en biblioteconomia”. Investigación Bibliotecológica: archivonomía, bibliotecología e información 32 (77): 57-72.

http://dx.doi.org/10.22201/iibi.24488321xe.2018.77.57867 